\title{
INVESTIGANDO ASPECTOS DA ALFABETIZAÇÃO CIENTÍFICA A PARTIR DE PRODUÇÕES ESCRITAS DE ESTUDANTES DO ENSINO MÉDIO
}

\section{Investigating Aspects of Scientific Literacy in Written Productions from High School Students}

\author{
Jean Karlo Silva de Miranda* \\ Wilmo Ernesto Francisco Junior ${ }^{* *}$
}

\begin{abstract}
Resumo: Este trabalho foi desenvolvido a partir de uma unidade didática sobre soluções aquosas, realizada com 40 estudantes do segundo ano do Ensino Médio de uma escola pública, com o intuito de contribuir para o processo de alfabetização científica. A unidade foi iniciada com uma situação problematizadora, apresentada por meio de uma estória em que três personagens expunham visões distintas acerca dos impactos ambientais em função do desastre ocorrido em Mariana/MG. Ao final, foi solicitado aos participantes para finalizarem a estória, que foi objeto de investigação por meio de análise de conteúdo. O objetivo foi avaliar o processo de alfabetização científica dos estudantes mediante a manifestação de indicadores. Os resultados mostraram diferentes indicadores de alfabetização científica, sendo o eixo compreensão de termos e conceitos o mais evidenciado (29 produções). Indicadores sobre as relações entre ciência e sociedade foram identificados em 22 produções e indicadores sobre a natureza da ciência apareceram em menor quantidade (seis produções). A produção textual mostrou-se adequada para a análise dos indicadores, inclusive por mostrar a ausência ou o silenciamento de alguns.
\end{abstract}

Palavras-chave: Alfabetização científica. Unidade didática. Soluções aquosas.

\begin{abstract}
This work was being developed from a didactic unit on aqueous solutions carried out with 40 students of the second year of High School in a public institution in order to contribute to the process of scientific literacy. The unit started with a problematic situation presented through a story in which three characters exposed different views regarding the environmental impacts due to the disaster that occurred in Mariana/MG. As a final step, the students were asked to end the story. These texts were analyzed in terms of content analysis in order to evaluate the students' scientific literacy process. The results showed different indicators of scientific literacy, with the understanding of terms and concepts being the most evident axis (29 productions). Indicators about relationship between science and society were identified in 22 texts and indicators concerning the nature of science appeared in a small quantity six texts. The textual production proved to be adequate for the analysis of the indicators, including by showing the absence or silencing of some aspects.
\end{abstract}

Keywords: Scientific literacy. Didactic unit. Aqueous solution.

\footnotetext{
* Mestre em Ensino de Ciências e Matemática pela Universidade Federal de Alagoas/UFAL. Docente da Escola de Referência em Ensino Médio de Arcoverde - Arcoverde, Pernambuco, BR. ORCID: https://orcid.org/00000002-7379-6279. E-mail: jean-karlo2005@bol.com.br.

** Doutor em Química (Educação Química) pelo Instituto de Química da UNESP Araraquara. Docente da UFAL, na Licenciatura em Química do Campus Arapiraca e nos PPG em Ensino de Ciências e Matemática (PPGECIM) e Educação (PPGE). ORCID: https://orcid.org/0000-0003-4591-4490. E-mail: wilmojr@ bol.com.br.
} 


\section{Introdução}

Pode-se afirmar que a sociedade está cada vez mais dependente de tecnologias e avanços proporcionados pela ciência. Isso, porém, implica em desafios maiores, especialmente, relacionados à sustentabilidade de recursos naturais e ao ambiente. Nesse contexto, a química ocupa lugar de destaque, conforme Mortimer et al. (2000, p. 274): "A Química, ciência central na concepção de novos materiais, pode oferecer respostas a essa diversidade de demandas, através do conhecimento sobre a constituição, propriedades e transformações das substâncias."

No entanto, muitas críticas já foram tecidas sobre o ensino dessa ciência de forma desvinculada da realidade, enfatizando aspectos conceituais pouco relevantes em detrimento a aspectos históricos e tecnológicos. O objetivo de preparar os estudantes para prestarem exames classificatórios, bem como a ênfase na memorização foram fatores decisivos para a rejeição por parte de muitos alunos (CHASSOT, 1995; 2011). Na década de 90, Chassot (1995) questionava para que $(m)$ seria útil um ensino cuja abordagem se ancorava na reprodução de informações pouco utilizadas pelos próprios químicos. Entre os exemplos, o autor apresentou as noções de átomos isótonos, isóbaros e isoeletrônicos. Diante do exposto, percebe-se a necessidade de se buscar uma abordagem que favoreça a formação da cidadania. Tal visão tem sido contemplada por pesquisas que visam à alfabetização científica (AC), termo originado de Scientific Literacy, expressão apresentada no trabalho de Paul Hurd (1958). Ainda em 1966, Pella et al. já discutiam a acepção do que seria um indivíduo alfabetizado cientificamente, pontuando sobre a importância de se conhecer as relações entre Ciência e Sociedade; o trabalho de cientistas; a natureza da ciência; diferenciar ciência de tecnologia; conceitos básicos das ciências; entender as relações entre as ciências e as humanidades.

No contexto brasileiro, muitos autores também se debruçam sobre a temática. Chassot (2011, p. 62), por exemplo, defende a AC como o "conjunto de conhecimentos que facilitariam aos homens e mulheres fazer uma leitura do mundo onde vivem". Em um texto de revisão, Sasseron e Carvalho (2011) discutem algumas expressões semelhantes usadas na literatura estrangeira para denominar a corrente da didática das ciências que investiga o ensino para a formação de sujeitos capazes de participar dos processos de tomada de decisões fundamentadas. Entre tais expressões aparecem Alfabetización científica, na língua espanhola; Scientific literacy - na língua inglesa, que vem sendo traduzida como letramento científico; e Alphabétisation scientifique - na francesa, que assim como a expressão espanhola, vem sendo traduzida como alfabetização científica. A tradução desses diferentes termos gerou controvérsias no Brasil (SASSERON; CARVALHO, 2011). Independentemente da tradução, não se deve considerar a scientific literacy como sendo simples, pois existem diferentes pontos de vista e interpretações sobre o que o público deve saber sobre ciências. É importante ainda assinalar que a alfabetização científica não ocorre apenas no espaço escolar e trata-se de um processo contínuo a partir do qual as pessoas podem apresentar diferentes graus de desenvolvimento.

Nesse contexto, surgiu a visão de que o termo é difuso e mal definido (LAUGKSCH, 2000), existindo o risco de que cada um atribua a sua própria definição (LORENZETTI; DELIZOICOV, 2001). Todavia, independentemente de possíveis diferenças:

Podemos perceber que no cerne das discussões levantadas pelos pesquisadores que usam um termo ou outro estão as mesmas preocupações com o ensino de Ciências, ou seja, motivos que guiam o planejamento desse ensino para a construção de benefícios práticos para as pessoas, a sociedade e o meio-ambiente (SASSERON; CARVALHO, 2011, p. 60). 
Baseando-se nas ideias de Paulo Freire, para o qual a alfabetização implica numa formação cidadã crítica que olhe o mundo e busque formas de intervenção de modo a melhorálo, Sasseron e Carvalho (2011) adotam o termo "alfabetização científica" como tradução para scientific literacy. Nesses termos, as autoras propõem três eixos balizadores para sua delimitação: i) Compreensão básica de termos, conhecimentos e conceitos científicos fundamentais; ii) Compreensão da natureza das ciências e dos fatores éticos e políticos que circundam sua prática; iii) Entendimento das relações existentes entre ciência, tecnologia, sociedade e meio-ambiente. Esses eixos foram denominados de estruturantes e coadunam-se ao estudo apresentado por Santos (2007) a partir de uma extensa revisão da literatura internacional. Neste caso, o autor apresentou os eixos: modelos e linguagem; natureza de ciência; e aspectos sociocientíficos. A diferença foi o uso do termo letramento científico pelo autor.

Para Sasseron e Carvalho (2011), o nível de AC dos estudantes pode ser avaliado e desenvolvido a partir de indicadores baseados em competências próprias da atividade científica e que não são mutuamente excludentes. São eles: a seriação de informações, a organização de informações, a classificação de informações, o raciocínio lógico, o raciocínio proporcional, o levantamento de hipóteses, o teste de hipótese, a justificativa, a explicação e a previsão de resultados. Tais indicadores são, portanto, destrezas necessárias para o fomento da AC entre os estudantes e podem, ainda, tornar o Ensino de Química algo mais plausível por aproximá-los do fazer científico. As autoras afirmam que:

\footnotetext{
Nossos indicadores têm a função de nos mostrar algumas destrezas que devem ser trabalhadas quando se deseja colocar a AC em processo de construção entre os alunos. Estes indicadores são algumas competências próprias das ciências e do fazer científico: competências comuns desenvolvidas e utilizadas para a resolução, discussão e divulgação de problemas em quaisquer das Ciências quando se dá a busca por relações entre o que se vê do problema investigado e as construções mentais que levem ao entendimento dele (SASSERON; CARVALHO, 2008, p. 338).
}

Aproximar os estudantes de uma prática científica, mais especificamente em química, também significa ajudá-los no entendimento dos modelos, haja vista que a química é uma ciência de elevado caráter abstrato. Nessa direção, Cachapuz et al. (2011) apresentam a tese segundo a qual é possível propor um currículo com um mínimo de conhecimentos específicos (acessíveis a todos) com abordagens globais e considerações éticas que permitam ao cidadão tomar decisões fundamentadas no conhecimento, avaliando-se seus riscos e benefícios.

Entre os conteúdos no currículo da química, o entendimento das soluções é crucial para a compreensão de muitos outros tais como propriedades coligativas, eletroquímica e equilíbrios químicos. Autores como Carmo e Marcondes (2008) e Echeverría (1996) explicam que as dificuldades para o aprendizado do conteúdo soluções se dão, entre outros fatores, devido à ênfase dada durante o processo de ensino aos aspectos macroscópicos e quantitativos do tema em detrimento às características submicroscópicas da estrutura da matéria.

Ortolani et al. (2012) sugerem, além da necessidade de se trabalhar os aspectos atômicos e moleculares, uma abordagem contextualizada e que faça sentido para os estudantes, permitindo que desenvolvam e utilizem os modelos científicos na resolução de variadas situações-problema. Tais situações podem ser organizadas por meio de um conjunto de atividades, denominado aqui de unidade didática. Sánchez-Blanco e Valcárcel-Pérez (1993, p. 33) consideram uma unidade didática como uma "lista flexível de ações centradas 
fundamentalmente nos conteúdos e nas atividades de ensino, estando implícitos os objetivos e metas a alcançar" (tradução nossa).

Nesses termos, o presente trabalho desenvolveu e aplicou uma unidade que enfocou o tema soluções aquosas com o intuito de favorecer a alfabetização científica. Tal unidade didática foi estruturada com base em modelo publicado por Sánchez-Blanco e Valcárcel-Pérez (1993) e tentando promover os eixos de AC propostos por Sasseron e Carvalho (2011). O objetivo desta pesquisa foi analisar sua contribuição para o processo de AC dos estudantes. A questão de investigação delineadora foi: que indicadores e eixos de alfabetização científica podem ser evidenciados a partir da escrita dos estudantes como atividade final da unidade didática?

\section{Metodologia}

A presente pesquisa foi realizada com estudantes do segundo ano do Ensino Médio de uma escola estadual em tempo integral, do sertão pernambucano, na qual um dos pesquisadores leciona química. A unidade didática elaborada foi fundamentada nas proposições sobre planejamento oriundas do trabalho de Sánchez-Blanco e Valcárcel-Pérez (1993), que propõem a organização de uma unidade didática em cinco etapas: a) Análise científica; b) Análise didática; c) Seleção de objetivos; d) Seleção das estratégias didáticas; e) Seleção das estratégias de avaliação. A análise científica é composta pela seleção, delimitação e atualização conceitual pelo professor, incluindo conceitos ligados à natureza da ciência e aos aspectos sociocientíficos. A análise das dificuldades de ensino e aprendizagem dos conteúdos e dos conhecimentos prévios necessários aos estudantes configuram a segunda etapa. Na sequência, vem o planejamento didático propriamente dito, com a definição dos objetivos de aprendizagem para os estudantes, as estratégias de ensino para promoção de tais objetivos e a seleção dos instrumentos de avaliação.

Para fundamentar o planejamento da unidade, foram consideradas as Orientações Curriculares para o Ensino Médio (OCEM) (BRASIL, 2008), as Orientações TeóricoMetodológicas para o Ensino Médio de Pernambuco na área de química (PERNAMBUCO, 2011), bem como nos eixos de AC propostos por Sasseron e Carvalho (2011). Cada etapa da unidade didática planejada é apresentada pelo Quadro 1.

Quadro 1 - Etapas desenvolvidas na Unidade Didática com seus respectivos objetivos e instrumentos.

\begin{tabular}{|c|c|c|}
\hline Etapa & Objetivo & Instrumento de avaliação \\
\hline $\begin{array}{l}\text { D1. Diagnóstico do } \\
\text { conhecimento dos estudantes. } \\
\text { Leitura do texto "Um Problema } \\
\text { de Todos" e exibição de vídeo } \\
\text { com reportagem sobre o } \\
\text { acidente ocorrido em Mariana, } \\
\text { MG, seguida de discussão } \\
\text { acerca da temática abordada. } \\
\mathrm{N}^{\circ} \text { de aulas: } 2 \text {. }\end{array}$ & $\begin{array}{l}\text { - Questionar os alunos a respeito do texto } \\
\text { "Um Problema de Todos": O problema é } \\
\text { mesmo de todos? Estamos cuidando dos } \\
\text { nossos mananciais? Quais são as } \\
\text { atividades humanas que mais trazem } \\
\text { prejuízo aos nossos mananciais na } \\
\text { atualidade? O que sabem sobre a tragédia } \\
\text { de Mariana, MG? }\end{array}$ & $\begin{array}{l}\text {-Questionário. } \\
\text { bordo. }\end{array}$ \\
\hline $\begin{array}{l}\text { 02. Exibição de vídeo da TV } \\
\text { Química Nova na Escola, } \\
\text { QNEsc, acerca das propriedades } \\
\text { da água, seguido de debate e } \\
\text { explanação sobre forças } \\
\text { intermoleculares e polaridade. } \\
\mathrm{N}^{\circ} \text { de aulas: } 2 \text {. }\end{array}$ & $\begin{array}{l}\text { - Compreender algumas propriedades da } \\
\text { água como sua geometria molecular, } \\
\text { polaridade, forças de interação } \\
\text { intermolecular; } \\
\text { - Compreender as etapas de tratamento da } \\
\text { água numa ETA; }\end{array}$ & - Diário de bordo. \\
\hline
\end{tabular}




\begin{tabular}{|c|c|c|}
\hline & $\begin{array}{l}\text { - Discutir a importância do consumo } \\
\text { consciente da água, bem como o problema } \\
\text { da poluição dos mananciais. }\end{array}$ & \\
\hline $\begin{array}{l}\text { 03. Atividade experimental: } \\
\text { Condutividade elétrica em } \\
\text { diferentes amostras de água. } \\
\mathrm{N}^{\circ} \text { de aulas: } 2 \text {. }\end{array}$ & $\begin{array}{l}\text { - Analisar a condutividade elétrica em } \\
\text { diferentes amostras de água: água } \\
\text { destilada, água da torneira, água mineral, } \\
\text { água de barreiro, água do bebedouro da } \\
\text { escola e água do mar; } \\
\text { - Propor hipóteses para cada um dos } \\
\text { experimentos e testá-las anotando suas } \\
\text { conclusões. }\end{array}$ & $\begin{array}{l}\text { - Questionário proposto no } \\
\text { roteiro experimental. }\end{array}$ \\
\hline $\begin{array}{l}\text { 04. Discussão conceitual acerca } \\
\text { dos resultados obtidos no } \\
\text { experimento } \\
\text { animação do Phet. } \\
\mathrm{N}^{\circ} \text { de aulas: } 2 .\end{array}$ & $\begin{array}{l}\text { - Comparação das conclusões obtidas por } \\
\text { aluno na atividade experimental; } \\
\text { - Compreender o processo de solvatação } \\
\text { do cloreto de sódio por meio do aplicativo } \\
\text { do Phet; } \\
\text { - Compreender o processo de dissolução } \\
\text { do açúcar comum na água. }\end{array}$ & - Dia \\
\hline $\begin{array}{l}\text { 05. Análise de rótulos de água } \\
\text { mineral e suco, seguida de } \\
\text { estudo dos tipos de dispersão - } \\
\text { suspensão, colóide e solução. } \\
\mathrm{N}^{\circ} \text { de aulas: } 2 \text {. }\end{array}$ & $\begin{array}{l}\text { - Compreender o que são soluções e a } \\
\text { diferença entre elas e os demais tipos de } \\
\text { dispersões (coloides e suspensões); } \\
\text { - Analisar rótulos de água mineral e suco } \\
\text { de caixinha. }\end{array}$ & $\begin{array}{l}\text { - Respostas dadas } r \text { ao } \\
\text { questionário proposto em } \\
\text { material elaborado pelo } \\
\text { professor, no qual também } \\
\text { consta o roteiro experimental. } \\
\text { - Diário de bordo. }\end{array}$ \\
\hline $\begin{array}{l}06 . \text { Discussão acerca das } \\
\text { respostas dadas às questões } \\
\text { propostas e orientações sobre a } \\
\text { escrita de texto com a } \\
\text { continuação da estória. } \\
\mathrm{N}^{\circ} \text { de aulas: } 2 \text {. }\end{array}$ & $\begin{array}{l}\text { - Corrigir as questões propostas nas aulas } \\
\text { anteriores sobre dispersões e análise de } \\
\text { rótulos; } \\
\text { - Orientar sobre a continuação do texto } \\
\text { "Um problema de todos", a qual será feita } \\
\text { pelos alunos no período extraclasse e } \\
\text { entregue em aula futura. }\end{array}$ & $\begin{array}{l}\text { - Respostas dadas } r \text { ao } \\
\text { questionário proposto em } \\
\text { apostila elaborada pelo } \\
\text { professor, na qual também } \\
\text { consta o roteiro experimental. } \\
\text { - Diário de bordo. }\end{array}$ \\
\hline
\end{tabular}

Fonte: Os autores (2018).

A unidade didática recebeu o título "O que tem na água?” e foi conduzida a partir da problematização do texto "Um Problema de Todos". Este texto é uma estória criada pelo professor/pesquisador da turma, abordando um diálogo entre três estudantes que pontuavam diferentes pontos de vista acerca dos impactos gerados com o desastre ambiental ocorrido no distrito de Mariana, Minas Gerais (MG), em novembro de 2015. Um dos estudantes alegava que eles não tinham nenhuma relação com aquilo e que o problema não afetaria a vida no local em que moravam. Outra estudante contrapunha-se a este argumento, afirmando que o problema era de todos. Um terceiro estudante apresentava uma visão mais neutra. A partir deste texto inicial, foram desenvolvidas todas as etapas e atividades, conforme Quadro 1, como se os estudantes fossem as próprias personagens. A última atividade foi justamente uma produção escrita, finalizando a estória e apresentando um posicionamento sobre a questão. Dessa forma, ao propor uma continuidade da estória, os estudantes participantes deveriam expor suas ideias e argumentos com base no conhecimento químico, o que permite avaliar indicadores de AC.

Tais textos produzidos pelos estudantes ao fim da unidade didática foram a fonte principal de dados desta pesquisa. Ao total, foram analisados 40 textos dos estudantes que participaram de todas as etapas e entregaram o Termo de Consentimento Livre e Esclarecido assinado pelos pais ${ }^{1}$. Todos os participantes tiveram suas identidades preservadas e cada produção recebeu um código aleatório. O material escrito foi tratado com base na análise de

\footnotetext{
${ }^{1}$ A presente pesquisa foi submetida e aprovada pelo Comitê de Ética na Pesquisa em 23/02/2017.
} 
conteúdo o qual é dividido basicamente em três fases (BARDIN,1977). Na primeira delas, a pré-análise, procedeu-se a leitura preliminar para o contato e organização do material. A segunda fase configurou-se pela exploração do material, com base na identificação das unidades de significado, classificação e categorização. A última fase constituiu-se do reagrupamento do conteúdo e análise reflexiva com o respectivo cotejamento teórico.

A identificação das unidades de significado foi pautada em categorias a priori, buscando-se evidências dos eixos estruturantes da AC: I) compreensão básica de termos, conhecimentos e conceitos científicos fundamentais; II) compreensão da natureza das ciências e dos fatores éticos e políticos que circundam sua prática e; III) entendimento das relações existentes entre ciência, tecnologia, sociedade e meio-ambiente (SASSERON; CARVALHO, 2011). Dentro de cada eixo, foram identificados como subcategorias os indicadores de alfabetização científica.

\section{Resultados e Discussão}

Uma primeira imersão nas produções demonstrou que a maioria dos trabalhos narrou as etapas experimentais realizadas pelas personagens da estória, indicando quais hipóteses foram levantadas, como foram testadas e a quais conclusões chegaram. Isso se deu, provavelmente, devido ao modo como o roteiro experimental foi elaborado. As etapas eram apresentadas como tendo sido realizadas pelas personagens Léo, Bia e Cadu. Assim, provavelmente os estudantes sentiram-se identificados com as personagens. A Tabela 1 apresenta os eixos estruturantes identificados e sua quantidade nas produções analisadas. Destaca-se que em muitos trabalhos foram identificados mais de um eixo.

Tabela 1 - Eixos estruturantes de AC identificados nas produções textuais.

\begin{tabular}{|l|c|}
\hline \multicolumn{1}{|c|}{ Eixo estruturante de AC } & Quantidade \\
\hline $\begin{array}{l}\text { Eixo I: Compreensão básica de termos, conhecimentos e conceitos científicos } \\
\text { fundamentais. }\end{array}$ & 29 \\
\hline $\begin{array}{l}\text { Eixo II: Compreensão da natureza das ciências e dos fatores éticos e políticos } \\
\text { que circundam sua prática. }\end{array}$ & 6 \\
\hline $\begin{array}{l}\text { Eixo III: Entendimento das relações existentes entre ciência, tecnologia, } \\
\text { sociedade e meio ambiente. }\end{array}$ & 22 \\
\hline
\end{tabular}

Fonte: Os autores (2018).

Em termos dos indicadores de AC, o Eixo I foi aquele em que mais se evidenciou a sua presença, sendo esses identificados em 29 , das 40 produções. Os conceitos e termos científicos mais utilizados estiverem relacionados aos íons, dissolução e à água destilada. O indicador explicação foi o mais presente.

Professor explicou dizendo: Léo, íons são átomos que perderam ou ganharam elétrons em razão de reações, eles se classificam em ânions e cátions. Ânion: átomo que recebe elétrons e fica carregado negativamente. Exemplos: N3-, Cl-, F-, O2-. Cátion: átomo que perde elétrons e adquire carga positiva. (A59) 
Essa etapa de escrita permitiu que os conceitos estudados fossem usados para produção das estórias e não meramente repetidos, visto que a aprendizagem "requer não apenas a compreensão de conceitos-chave, mas também o estabelecimento de vínculos significativos para trazer os conceitos a um todo coerente" (SIRHAN, 2007, p. 8, tradução nossa). A produção também permitiu identificar erros conceituais. O problema mais comum foi a falta de distinção entre compostos caracterizados como iônicos (formados por íons que se mantêm unidos numa estrutura pela atração eletrostática) e moleculares (formados por moléculas). Dois estudantes descreveram o sal de cozinha (composto iônico formado por íons sódio e cloreto) como um composto molecular, ao passo que outros dois classificaram o açúcar (composto formado por moléculas de sacarose) como iônico. Em quatro trabalhos, houve tentativa de explicar a dissolução em água e seus efeitos, mas a partir do uso inadequado de justificativas. Para dois estudantes, a corrente elétrica do circuito não vinha de uma fonte externa, mas sim da água com sal, concepção alternativa que fica evidente no trecho a seguir: "Vejam, pessoal! A condutividade na água do mar é visivelmente crescente. A salinidade da água do mar é grandiosa e o sal quando dissolvido em água produz uma corrente elétrica favorável para que, por exemplo, a luz acenda." A05 (Grifo dos autores).

Não obstante a informação selecionada (condutividade na água do mar é crescente) seja relevante e devidamente justificada (salinidade da água do mar é grandiosa), a explicação não se pauta em um modelo aceito para o tema em questão. De fato, trata-se de uma concepção alternativa já detectada na etapa quatro da unidade (a solução aquosa gera energia elétrica). Naquela ocasião, e, também em etapas posteriores (uso de simulações sobre a dissolução de compostos iônicos), foi discutido que a energia elétrica não é gerada pela solução de água e sal, mas proveniente da rede elétrica, sendo a lâmpada um instrumento de verificação da condutividade devido à presença de íons dissolvidos.

Ortolani et al. (2012) afirmam que uma única unidade de ensino não é suficiente para levar todos os estudantes a substituírem esquemas alternativos de explicação por aqueles subsidiados em modelos aceitos pela ciência. Todavia, a produção textual permitiu identificar inconsistências conceituais que podem ser novamente debatidas em sala de aula.

Outros dois textos exibiram como indicadores explicações e justificativas mais complexas, baseadas inclusive em outras fontes que não as apresentadas pelo docente. Destacase, a seguir, um trecho da estória produzida por A47, que apresentou uma explicação mais pormenorizada sobre a condutividade elétrica:

\footnotetext{
Sim, corrente elétrica. Esta capacidade é devido à presença de íons, sua concentração, mobilidade e valência, bem como a temperatura do ambiente. A água destilada tem uma condutividade de 0,5 a $3 \mu \mathrm{mhos} / \mathrm{cm}$, com baixíssima quantidade de eletrólitos e, por seguinte, também possui baixa condução elétrica, por isso a lâmpada não acende - Respondeu o professor.
}

Neste excerto, verifica-se o uso de argumentos, sendo a afirmação devidamente justificada com base em termos, conceitos e suas relações. São verificadas as capacidades de organização e classificação de informações, justificativa, explicação e conclusão, indicadores estabelecidos por Sasseron e Carvalho (2008). A elaboração de justificativas fundamentadas exige seleção de evidências relevantes a partir de dados, assim como a construção de relações coerentes com os modelos e teorias correspondentes (JUSTI, 2015). A argumentação é tida como o meio pelo qual se encontram evidências do pensamento científico (SASSERON; CARVALHO, 2008). Nota-se ainda o uso de retóricas de persuasão, ao concluir o trecho com 
"Respondeu o professor". Assim, evidencia-se um elevado grau de elaboração textual e conceitual por parte do estudante. Acrescenta-se o fato de ponderar informações novas, não apresentadas em sala de aula. Ao extrapolar as informações fornecidas, tem-se um indicativo da autonomia do estudante e seu protagonismo no processo de aprendizagem.

Todavia, tal grau de elaboração não foi recorrente nos textos produzidos (verificado em cerca de 5\% das produções). Ao mesmo tempo em que se reconhece a importância da comunicação escrita como meio de materializar e investigar o pensamento científico, deve-se ressaltar o grau de exigência dessa atividade. É comum, portanto, que um grupo heterogêneo apresente diferentes níveis para o uso da linguagem e termos científicos. Outro aspecto a ser ressaltado foram as próprias orientações quanto à produção textual, as quais não enfatizaram a necessidade de uso dos conceitos estudados, o que se somou às dificuldades e ao possível não reconhecimento deste aspecto por parte dos estudantes na comunicação escrita. Tais resultados apenas reforçam a necessidade de que as propostas de ensino sistematizem atividades pelas quais o pensamento científico dos estudantes seja favorecido. O fato de 29 das 40 produções apresentarem algum indicador relacionado à apropriação da linguagem, teoria ou modelos científicos, apontam a importância do conjunto de atividades para o desenvolvimento deste quesito. Por outro lado, os diferentes graus de complexidade demonstram a necessidade de se pensar em tais requisitos.

No que tange ao eixo II (compreensão da natureza das ciências e dos fatores éticos e políticos que circundam sua prática), procurou-se fragmentos textuais que demonstrassem uma compreensão por parte dos educandos da forma como o conhecimento químico é produzido (aproximação dos estudantes à cultura científica), incluindo o fato de que a química, como qualquer ciência, não é algo estático ou imparcial. Indicadores identificados dentro deste eixo distribuíram-se entre organização de informações, raciocínio lógico, explicação, previsão e justificativa.

$\mathrm{Na}$ narrativa a seguir, o educando traz diálogos nos quais as personagens discorrem acerca das análises, feitas nas águas do Rio Doce, e encomendadas por diferentes segmentos (organização de informações), apontando que as análises detectaram metais pesados (justificativa): “A Samarco afirmou que não havia provas de contaminação por metais pesados, mas as reportagens mostravam e as análises feitas, que detectou sim metais pesados em níveis acima do permitido nas águas atingidas pelos rejeitos - corroborou o professor de química." (A50).

Isso demonstra a apropriação de debates realizados em sala de aula. Na etapa 2 da unidade, foram comparados dados das análises solicitadas pela Federação Nacional dos Médicos (FENAM) com aqueles oriundos de empresas contratadas pela Samarco, mostrando as contradições existentes. Na ocasião, foi discutida a não neutralidade da ciência e o fato dela ser circundada por fatores políticos e econômicos. Naquela aula, os estudantes afirmaram a maior confiabilidade nos laudos da FENAM e não da Samarco. Tais debates fomentam a construção de uma maior criticidade por parte dos educandos, permitindo que muitos abandonem a concepção de ciência como algo infalível, exato e neutro para uma visão de constructo humano e, como tal, passível de erros e propensa à manipulação por interesses econômicos e/ou políticos. É função do ensino de ciências que vise à alfabetização científica a promoção de condições necessárias à realização de leituras críticas da realidade, participação no debate público, tomada de decisão referenciado no conhecimento historicamente acumulado, bem como intervenção social em uma perspectiva emancipadora (MARQUES; MARANDINO, 2018). 
Outra narrativa (escrita por A60) deixa evidente as relações entre fatores políticos e financeiros que podem perpassar a atividade científica e tecnológica. Notam-se questionamentos retóricos e construção de argumentos sobre a razão do acontecimento (ambição humana, onde o dinheiro vem sempre antes).

\begin{abstract}
- Sempre soube que deveríamos ter muito cuidado com a nossa água [...] infelizmente uma área muito extensa do nosso país foi afetada por causa da ambição humana, onde dinheiro vem sempre antes que a natureza e a qualidade de vida da população, e agora querem pagar o que foi perdido da natureza, porém o que era da natureza não se negocia. Quantos não entraram em depressão com tais acontecimentos? Quantos ficaram desabrigados, sem rumo na vida? - Completou Cadu.
\end{abstract}

Percebe-se uma conotação de revolta com o descaso. Entretanto, o argumento não se constrói por meio de um aspecto técnico, sobre a negligência das condições da barragem para a manutenção da operação da mineradora, mas por uma hipótese de ambição financeira. Assim, percebe-se um raciocínio lógico de caráter pessoal. As perguntas retóricas também funcionam como previsão das consequências. Ainda que não haja uma relação inequívoca entre lucro financeiro e descaso com a barragem, isto é, entre a evidência e a afirmativa, também não se pode negar essa relação. Em outras palavras, o argumento apresenta uma justificativa implícita assentada na não neutralidade técnico-científica.

Conquanto a existência de momentos em que se tenha discutido a ciência como uma produção humana, não neutra, controversa, este eixo foi o menos explorado nas narrativas (em apenas seis das 40), demonstrando necessidade de maior compreensão das características do trabalho científico. Por ora, vale refletir com Díaz et al. (2003), a impossibilidade de um modelo universal para a promoção da alfabetização científica, bem como o caráter processual de seu desenvolvimento. Nesse sentido, é pouco factível que um mesmo conjunto de atividades seja capaz de abarcar finalidades tão amplas e distintas. Ainda vale pontuar o limitante da produção textual, pois nem tudo considerado relevante por parte dos estudantes pode ter sido expresso.

No que diz respeito ao eixo III (entendimento das relações existentes entre ciência, tecnologia, sociedade e meio ambiente), pode-se perceber preocupações com o uso social do conhecimento e a presença de respectivos indicadores em vinte e duas narrativas $(55,0 \%)$.

Houve aqueles que destacaram dados acerca da tragédia no distrito de Mariana deixando clara a indignação nas falas das personagens acerca do ocorrido, bem como em relação à impunidade dos respectivos responsáveis.

O Rio Doce é “casa” para diversas espécies e inclusive, após essa tragédia, algumas espécies que só existem lá correm o risco de entrar em extinção - conclui o professor.

Professor, o fato é que eu e os meninos tivemos uma pequena noção de que a contaminação da água do Rio Doce foi grandiosa - afirmou Bia. (A05).

Sempre soube que deveríamos ter muito cuidado com a nossa água [...] infelizmente uma área muito extensa do nosso país foi afetada por causa da ambição humana, onde dinheiro vem sempre antes que a natureza e a qualidade de vida da população, e agora querem pagar o que foi perdido da natureza, porém o que era da natureza não se negocia. Quantos não entraram em depressão com tais acontecimentos? Quantos ficaram desabrigados, sem rumo na vida? - Completou Cadu. (A60) 
Os estudantes utilizam dados trazidos na situação problematizadora para justificar seu ponto de vista, concluindo que a contaminação foi "grandiosa", alcançando proporções que estão na ordem psicológica também. Dessa forma, percebe-se posicionamentos ante à tragédia com o uso de argumentos, relações de causa e efeito, sendo essa uma das características da alfabetização científica (SASSERON; CARVALHO, 2011).

Outros educandos demonstraram preocupação com a recuperação dos ecossistemas atingidos, bem como reflexões sobre como o processo poderia ser arrolado, sobre seus custos e tempo.

- Galera, eu li que os ambientalistas acreditam na recuperação do Rio, mas não se sabe quanto tempo nem quanto isso vai custar.

- Creio que não vai ser nada barato - disse Bia.

- É, levará muito tempo - Cadu respondeu.

- É preciso restabelecer a oxigenação da água, tirar a lama que nela está, causadora das mortes dos peixes, pois não deixa a luz entrar na água impedindo a oxigenação disse Léo. (A45)

Nota-se previsão, levantamento de hipótese, justificativa e explicação. Tais indicadores são importantes para a tomada de decisões e aplicação dos conhecimentos científicos na resolução de problemas cotidianas, sendo características para a alfabetização científica (CHASSOT, 2011; SASSERON; CARVALHO, 2011). Além de evidenciar o uso social do conhecimento científico, nota-se outro indicador importante, de caráter argumentativo e coerente conceitualmente, em que os processos de recuperação são justificados, o que caracteriza a compreensão básica de termos.

Percebeu-se que nessa atividade, mais da metade dos estudantes (22) demonstraram-se instigados a não só avaliar as problemáticas, mas também propor outras ações.

- Ao perguntar ao professor como aplicar essas coisas no nosso dia a dia evitando a poluição da água ele me deu quatro dicas: Não jogar lixo em rios, praias e lagos, não descartar óleo na rede de esgoto, não utilizar agrotóxicos em fontes hídricas e não desviar esgoto doméstico para córregos.

- Minha mãe sempre descartava o resto do óleo nos esgotos, interessante essa pesquisa - afirmou Léo.

Conforme argumenta Chassot (2011), a alfabetização científica não seria apenas uma forma das pessoas compreenderem melhor o mundo em que vivem, mas, a partir desse conhecimento, poder intervir nele. Tal aspecto associa-se ao uso social do conhecimento e adquire relevância na medida em que o sujeito reconhece seu papel de protagonista na sociedade. Tais dados corroboram a proposição de Sasseron e Carvalho (2011) para o eixo entendimento das relações existentes entre ciência, tecnologia, sociedade e meio-ambiente que:

[...] denota a necessidade de se compreender as aplicações dos saberes construídos pelas ciências considerando as ações que podem ser desencadeadas pela utilização dos mesmos. O trabalho com este eixo deve ser garantido na escola quando se tem em mente o desejo de um futuro sustentável para a sociedade e o planeta (SASSERON; CARVALHO, p. 76, 2011). 
Indubitavelmente, a situação didática escolar é um início da Alfabetização Científica que cria oportunidades para se discutir problemas da sociedade em conjunto aos temas da ciência. A efetiva participação social se daria em outra esfera que extrapola os muros escolares, mas que, por seu turno, só é materializada a partir da compreensão dessas situações no dia-adia, reafirmando o papel da escola, não como único espaço, mas como necessário para que tais discussões aconteçam.

Também ficou evidente que muitos dos sujeitos da pesquisa procuraram dados sobre poluição, especialmente, por metais pesados, para subsidiar seus argumentos.

\begin{abstract}
O professor também explicou, Léo, o descarte de resíduos industriais é a principal fonte de contaminação dos rios com metais pesados. Alguns processos de produção, entre os quais das indústrias metalúrgicas, de tintas, de cloro e plástico PVC, utilizam estes metais que, quando lançados irregularmente nos esgotos, contaminam os cursos de água. Entre os principais elementos tóxicos despejados estão o mercúrio, chumbo, cádmio, arsênico, bário, cobre, cromo e zinco.
\end{abstract}

\begin{abstract}
Além das atividades industriais, a incineração de lixo urbano também produz fumaças ricas em metais, principalmente mercúrio, chumbo e cádmio. Todos os metais resultantes destes processos podem ser solubilizados pela água, causando danos à saúde do homem e de animais, [...] como disfunções do sistema nervoso e aumento da incidência de câncer.
\end{abstract}

Alguns estudantes citaram o fato de a água, mesmo estando incolor, inodora e insípida, poder estar contaminada com metais pesados, sendo importante os órgãos competentes efetuarem análises na água a ser consumida. Em muitos trabalhos, os educandos demonstraram preocupação com a divulgação do que estava sendo estudado, afirmando que a população deve ser esclarecida:

É gente, eu nunca tinha pensado desse modo, pois achava que na água não tinha nada, pelo fato de ser incolor e sem gosto. Mas todos esses pensamentos mudaram depois das conversas com vocês [...]. Agora vou falar sobre tudo que aprendi pra minha família, pra eles cuidarem bem da água. (A36).

A necessidade de divulgação do conhecimento adquirido demonstra uma responsabilidade social por parte do educando (SANTOS, 2007), compreendendo que o conhecimento não deve ficar restrito a um grupo, mas deve ser compartilhado de modo a proporcionar novas compreensões e tomadas de decisão. Este é um fato relevante na ciência, pois a etapa de comunicação dos resultados, tanto entre os pares, como para a população, é intrínseca à própria ciência e funciona para a validação do conhecimento.

\title{
4 Considerações Finais
}

O eixo I foi o mais evidenciado com a presença de indicadores nas produções (29 ao total). Todavia, em muitos casos, os conceitos ou termos químicos não foram empregados adequadamente ou de modo mais consistente para justificar pontos de vista. Obviamente que na argumentação científica é esperado o uso de conceitos que fundamentem os posicionamentos. O uso dos termos e conceitos científicos não foram explicitamente solicitados ou assinalados como necessários para a continuidade da estória. Isso pode ter feito com que os estudantes não apresentassem maior preocupação com a articulação dessas ideias. 
O eixo II, no entanto, foi pouco evidenciado, a despeito do planejamento de atividades para a discussão da não neutralidade da ciência, por meio dos laudos controversos, e com atividades cuja proposta era aproximar os educandos de uma cultura científica (por meio do levantamento de hipóteses, teste de hipóteses e previsões dos resultados de fenômenos observados). Essa dimensão da ciência talvez não tenha sido vista como importante pelos participantes, indicando a necessidade de uma problematização ainda maior. Os indicadores de AC mais comuns nos textos foram a seriação de informação, a explicação e a justificativa, pois os alunos souberam utilizar dados apresentados nos textos fornecidos ou por eles pesquisados em outras fontes.

O eixo III também foi recorrente. Mais da metade dos trabalhos analisados apresentaram indicadores sobre as relações entre a ciência, a tecnologia, a sociedade e o meio ambiente. Os estudantes demonstraram tais aspectos por meio de fragmentos nos quais refletiam acerca da situação dos moradores do distrito de Mariana, no intuito de evitar a poluição por metais pesados, os riscos que estes trazem à saúde humana e ao meio ambiente, bem como formas de identificação da contaminação da água. Provavelmente, o apelo emocional proporcionou reflexões mais profundas gerando mais aprendizado sobre a química como construção humana.

Por fim, vale ainda sublinhar que o processo de Alfabetização Científica é gradual e processual e, evidentemente, uma única unidade de ensino é insuficiente para que os estudantes desenvolvam mais profundamente aspectos tidos como importantes para a formação da cidadania. Indubitavelmente, este é um indicativo que o trabalho na perspectiva da alfabetização científica deve permear constantemente as ações pedagógicas. Por fim, a produção textual discursiva, mediante a construção da estória, mostrou-se adequada para a análise dos indicadores de alfabetização científica, inclusive por mostrar a ausência ou o silenciamento de alguns.

\section{Referências}

BARDIN, L. Análise de conteúdo. Tradução de Luís Antero Reto e Augusto Pinheiro. Lisboa: Edições 70, 1977.

BRASIL. Ministério da Educação. Orientações Curriculares para o Ensino Médio: Ciências da Natureza, Matemática e suas Tecnologias. Brasília, DF: Secretaria de Educação Básica, 2008.

CACHAPUZ, A.; GIL-PÉREZ, D.; CARVALHO, A. M. P.; PRAIA, J.; ILCHES, A. A necessária renovação do ensino das ciências. 2. ed. São Paulo: Cortez, 2011.

CARMO, M. P.; MARCONDES, M. E. R. Abordando soluções em sala de aula: uma experiência de ensino a partir das ideias dos alunos. Química Nova na Escola, v. 28, n. 2, p. 37-41, 2008.

CHASSOT, A. I. Para que(m) é útil o ensino? Canoas: ULBRA, 1995. 196p.

CHASSOT. Alfabetização Científica: Questões e desafios para a educação. 5. ed. Injuí: Editora Unijuí, 2011. 
DÍAZ, J. A. A., ALONSO, A.V.; MAS, M.A.M. Papel de la Educación CTS en una Alfabetización Científica y Tecnológica para todas las Personas". Revista Electrónica de Enseñanza de las Ciencias, v. 2, n. 2, p. 80-111, 2003.

ECHEVERRÍA, A. R. Como os estudantes concebem a formação de soluções. Química Nova na Escola, v. 3, p.15-18, 1996.

HURD, P. H. Science literacy: its meaning for American schools. Educational Leadership, v. 16, n. 1, p. 13-16, 1958.

JUSTI, R. Relações entre argumentação e modelagem no contexto da ciência e do ensino de ciências. Ensaio: Pesquisa em Educação em Ciências, v. 17, p. 31-48, 2015.

LAUGKSCH, R. C. Scientific literacy: a conceptual overview. Science Education, v. 84, n. 1, p. 71-94, 2000.

LORENZETTI, L.; DELIZOICOV, D. Alfabetização científica no contexto das séries iniciais. Ensaio: Pesquisa em Educação em Ciências, v. 3, n. 1, p. 1-17, 2001.

MARQUES, A. C. T. L.; MARANDINO, M. Alfabetização científica, criança e espaços de educação não formal: diálogos possíveis. Educação e Pesquisa, v. 44, p. 1-19, 2018.

MORTIMER, E.; MACHADO, A. H.; ROMANELLI, L. I. A proposta curricular de Química do estado de Minas Gerais: fundamentos e pressupostos. Química Nova, v. 23, n. 2, p.273$283,2000$.

ORTOLANI, A.; FALICOFF, C.; CASTIÑEIRAS, J. M. D.; ODETTI, H. Aplicación de una propuesta de enseñanza sobre el tema "disoluciones" en la escuela secundaria: un estudio de caso. Educación Química, v. 23, n. 2, p. 212-221, 2012.

PELLA, M. O.; O'HEARN, G. T.; GALE, C. W. Referents to scientific literacy. Journal of Research in Science Teaching, v. 4, n. 3, p. 199-208, 1966.

PERNAMBUCO. Secretaria de Educação do estado. Orientações teórico-metodológicas para o Ensino Médio, Química. Recife, 2011. Disponível em:

<http://www.educacao.pe.gov.br/portal/upload/galeria/1037/OrientacoesTM_QuimicaEM.pdf $>$ Acesso em: 04 nov. 17.

SÁNCHEZ BLANCO, G.; VALCÁRCEL PÉREZ, M.V. Diseño de unidades didácticas en el área de ciencias experimentales. Enseñanza de las ciencias, v. 11, n. 1, p. 33-44, 1993.

SANTOS, W. L. P. Educação científica na perspectiva de letramento como prática social: funções, princípios e desafios. Revista Brasileira de Educação, v. 12, n. 36, p. 474-550, 2007.

SASSERON, L. H.; CARVALHO, A. P. Almejando alfabetização científica no Ensino Fundamental: a proposição e a procura de indicadores do processo. Investigações em ensino de ciências, v. 13, n. 3, p. 333-352, 2008. 
SASSERON, L. H.; CARVALHO. Alfabetização científica: uma revisão bibliográfica. Investigações em ensino de ciências, v. 16, n. 1, p. 59-77, 2011.

SIRHAN, G. Learning difficulties in Chemistry: an overview. Journal of Turkish Science Education, v. 4, n. 2, p. 2-20, 2007.

Recebido em dezembro de 2019.

Aprovado em maio de 2020. 